\title{
The Usefulness of Implicit Measures for the Screening, Assessment and Treatment of Problematic Alcohol Use in Individuals with Mild to Borderline Intellectual Disability
}

\author{
Neomi van Duijvenbode ${ }^{1,6} \cdot$ Robert Didden $^{1,2}$ - Hubert P. L. M. Korzilius ${ }^{3}$. \\ Rutger C. M. E. Engels ${ }^{4,5}$
}

Published online: 7 December 2016

(C) The Author(s) 2016. This article is published with open access at Springerlink.com

\begin{abstract}
Although the neuropsychological underpinnings of problematic alcohol use have been studied extensively, this research has not yet been generalised to individuals with mild to borderline intellectual disability (MBID). In this paper, we present the main findings of a research project aimed at studying the deficiencies in information processing associated with problematic alcohol use in problematic drinkers with and without MBID. The objectives were to develop and test indirect measures of cognitive biases and executive dysfunctioning of problematic drinkers with MBID and studying the extent and nature of the influence of IQ and executive control on these deficiencies. In addition to extending the fundamental knowledge about problematic alcohol use, the research findings provide practical implications that can be translated into the screening, assessment and treatment of problematic drinkers - both with and without MBID. Based on our results, we discourage the use of indirect, reaction time-based measures for cognitive biases for clinical purposes. The word association task, on the other hand, provides better opportunities, for example as a way to identify high-risk situations for alcohol use. With regard to
\end{abstract}

Neomi van Duijvenbode

n.vanduijvenbode@pwo.ru.nl

1 Behavioural Science Institute, Radboud University, P.O. Box 9104, 6500 HE Nijmegen, The Netherlands

2 Trajectum, P.O. Box 40012, 8004 DA Zwolle, The Netherlands

3 Institute for Management Research, Radboud University, P.O. Box 9108, 6500 HK Nijmegen, The Netherlands

4 Trimbos Institute, P.O. Box 725, 3500 AS Utrecht, The Netherlands

5 Faculty of Social Sciences, Utrecht University, P.O. Box 80140, 3508 TC Utrecht, The Netherlands

6 Pluryn, P.O. Box 53, 6500 AB Nijmegen, The Netherlands cognitive and executive functioning, we advise practitioners to conduct a thorough assessment in an early phase of the treatment but withhold from incorporating neurocognitive treatment protocols in the treatment of problematic alcohol use.

Keywords Problematic alcohol use · Implicit measures · Intellectual disability $\cdot$ Practical implications

\section{Introduction}

There is a growing body of research on (problematic) substance use among individuals with mild to borderline intellectual disability (MBID; IQ 50-85, American Psychiatric Association [APA] 2013). In fact, they have been identified as a risk group for more severe negative consequences of substance use (Slayter 2008) and for developing problematic substance use or substance use disorder (Burgard et al. 2000; McGillicuddy 2006). Despite this increasing attention, however, the current knowledge on problematic substance use in individuals with MBID is still scarce, and screening, assessment and treatment tools adapted to this population are lacking. In addition, professionals in both intellectual disability services (ID services) and addiction medicine often report having insufficient knowledge and skills to adequately care for individuals with MBID who (ab)use substances. As a result, individuals with MBID often do not receive the required specialised care and do not always profit from treatment (e.g. Burgard et al. 2000; Degenhardt 2000). Thus, there is a need for more research to improve the care and treatment of individuals with MBID who have problematic substance use (Carroll Chapman and Wu 2012; Van Duijvenbode et al. 2015; Kerr et al. 2013).

We have addressed this need by studying the neuropsychological underpinnings of problematic substance use. 
Problematic substance use has been associated with disruptions in the motivational, reward and inhibitory control processes and subsequent deficiencies in information processing (Koob 2013; Hyman et al. 2006; Nestler 2005). For example, as a result of adaptations in the motivational and reward systems, the rewarding effects of substances and related stimuli acquire 'incentive salience'. This means that these stimuli seem attractive, 'grab attention' and elicit approach behaviour (Robinson and Berridge 2008). These disruptions have been called cognitive biases. Several cognitive biases have been identified, including biases in attention, action tendencies and memory associations. Problematic substance use has also been related to a disrupted inhibitory control system, which is reflected in executive dysfunctioning (i.e. a smaller working memory capacity, difficulty in delaying gratification and less behavioural control; Hyman et al. 2006). Together, these disruptions indicate a growing loss of control over substance use in the development of problematic substance use and substance use disorder (Koob 2013).

Studying the neuropsychological underpinnings of problematic substance use may have important practical implications for screening, assessment and treatment (Stacy and Wiers 2010; Yücel and Lubman 2007). First, measures of cognitive biases are thought to be useful for screening and assessment purposes. For example, as cognitive biases appear to reduce as a consequence of treatment, the strength of the biases at the start of the treatment may serve as a predictor of treatment outcome while the reduction in strength at posttreatment may have utility as an assessment tool for treatment outcome. Second, recent research also suggests that directly influencing the strength of the cognitive biases in so-called cognitive bias modification procedures may provide an additional aspect of the treatment of problematic substance use. Third, the diagnostic and treatment process could also target the motivation and ability to control the implicit processes, for example by training executive control. Research has suggested that working memory training is feasible and effective for use in individuals with MBID (e.g. Van der Molen et al. 2010). As measures of both cognitive biases as well as executive control often do not rely on verbal capacity, are less susceptible to social desirability and are generally easy to complete, they might be especially useful in the care for problematic drinkers with MBID.

\section{Method}

The overall aim of our research project was to study the deficiencies in information processing associated with problematic alcohol use in problematic drinkers with and without MBID. We thereby focused on (problematic) alcohol use, because alcohol has been found to be the main substance used and misused by individuals with MBID (To et al. 2014). The objectives of our research project were to (1) develop and test indirect measures of cognitive biases and executive dysfunction for problematic drinkers and (2) study the extent and nature of the influence of IQ and executive control on these deficiencies by comparing individuals with and without MBID.

To meet the aims and objectives, ten cross-sectional studies were conducted. In all our studies, participants were divided into four groups based on full-scale IQ (as measured with the Wechsler Adults Intelligence Scale third edition [WAIS-III], Uterwijk 2000) and severity of alcohol use-related problems (as measured with the Alcohol Use Disorder Identification Test [AUDIT], Babor et al. 2001; Dutch translation: Schippers and Broekman 2010): light and problematic drinkers with and without MBID. Participants were recruited from organisations within ID care and addiction medicine and via advertisements on social media, the Radboud University and word of mouth. The characteristics of the studies included in this project are summarised in Table 1.

The first part of the research project consisted of four studies focussing on the existence of cognitive biases in attention and approach tendencies in problematic drinkers. We have studied the cognitive biases with implicit measures, which provide indirect measures of attention and approach tendencies derived from reaction times (RT). Such measures are thought to tap into automatic cognitive processes (Wilson et al. 2000) and are thought to reduce self-representation influences or social desirability (Greenwald et al. 2002; Stacy and Wiers 2010). The second part of the research project consisted of two studies on the interpretation bias or the tendency for problematic drinkers to interpret ambiguous, alcohol-relevant words, phrases and scenarios in an alcohol-related way. The interpretation bias is often studied using word association tasks, in which participants are asked to generate their first, spontaneous response when hearing an ambiguous, alcohol-relevant word, sentence or scenario (such as 'draft' or 'pitcher'). Although participants are asked about automatic associations and interpretations, they can assert control over their responses (Ranganath et al. 2008). The third part of the research project consisted of four studies focussing on the executive and cognitive functioning of problematic drinkers. Executive functioning was studied using computerised versions of executive functioning tests, which have become increasingly popular over the past decade (Josman et al. 2008). Cognitive functioning was studied with a standardised intelligence test.

\section{Results}

\section{Cognitive Biases}

To study cognitive biases in problematic drinkers, we first created a large database of pictures of alcoholic and nonalcoholic beverages that are sufficiently familiar and simple to study automatic processing (study 1; Van 


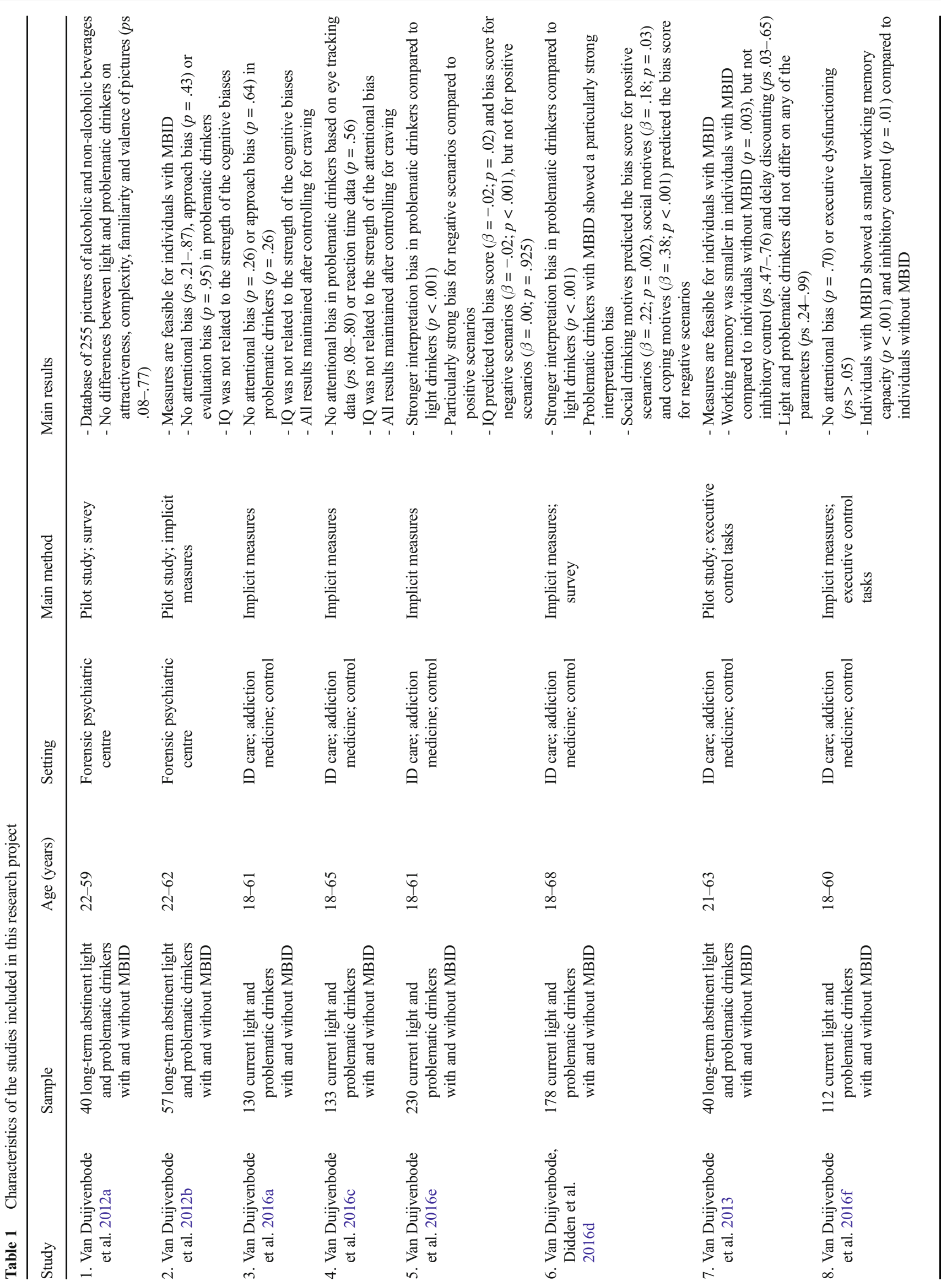


Duijvenbode et al. 2012a). We then adapted two widely used computer tasks (the visual dot probe task [VDP], MacLeod et al. 1986; approach avoidance task [AAT], Rinck and Becker 2007) to the needs of individuals with MBID by increasing the number of practice trials, minimising the number of critical trials and building in frequent breaks in between the different blocks of the tasks (study 2; Van Duijvenbode et al. 2012b). Figure 1 shows a schematic overview of both tasks. In this pilot study, it was concluded that - with the adaptations in the task characteristics - the VDP and AAT are feasible in individuals with MBID.

Using these tasks, we then conducted two studies in current drinkers to study the existence of cognitive biases. Unexpectedly, we found no evidence for an attentional or approach bias in problematic drinkers. Problematic drinkers neither responded faster than light drinkers to pictures of alcoholic beverages nor were they more likely than light drinkers to direct their attention towards pictures of alcoholic beverages or look at these pictures longer than do light drinkers (also see Hobson et al. 2013; Vollstädt-Klein et al. 2009). Noteworthy is the large variation in bias scores in problematic drinkers we found in our study, of whom some showed biases towards alcohol and others biases away from alcohol (studies 3 and 4; Van Duijvenbode et al. 2016a; Van Duijvenbode et al. 2016c). Estimated full-scale IQ was not associated with the strength of the attentional or approach bias, suggesting that the automatic, implicit processing of visual stimuli is similar between individuals with and without MBID.

\section{Interpretation Bias}

We did find evidence for an interpretation bias in the same sample of problematic drinkers (study 5; Van Duijvenbode et al. 2016e). We studied the interpretation bias using a word association task in which participants were asked to finish ambiguous scenarios with their first, spontaneous response (see Table 2 for an example of the scenarios we used; Woud et al. 2012). Problematic drinkers were more likely to interpret these scenarios in an alcohol-related way. This is in line with a large body of research, which has consistently found an interpretation bias in problematic drinkers (e.g. Ames et al. 2005; Krank et al. 2010; Woud et al. 2012, 2014). Estimated fullscale IQ was related to the strength of the interpretation bias, with a relatively strong bias in individuals with MBID. These results remained when controlling for (estimated) verbal IQ, suggesting that verbal capacity did not play a role in the assessment of the interpretation bias.

These results were replicated in our second study on this topic, in which we studied the relationship between the interpretation bias and drinking motives (Study 6; Van Duijvenbode et al. 2016d). The activation of the interpretation bias seemed to depend on individual differences in 
a

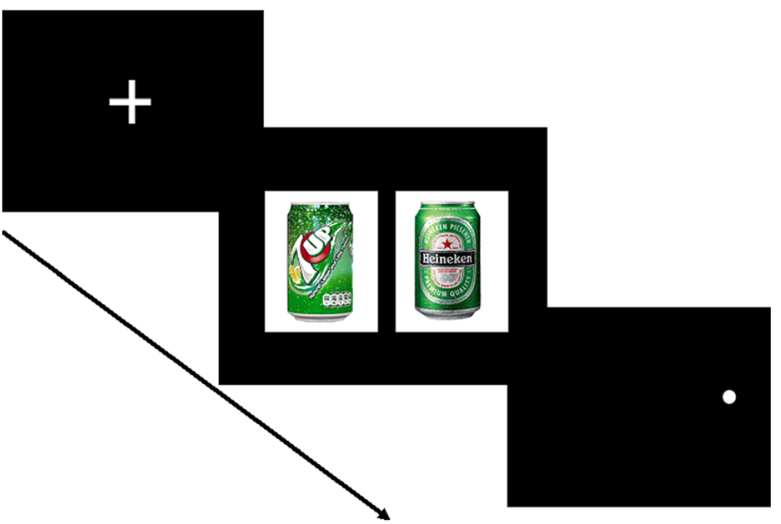

b

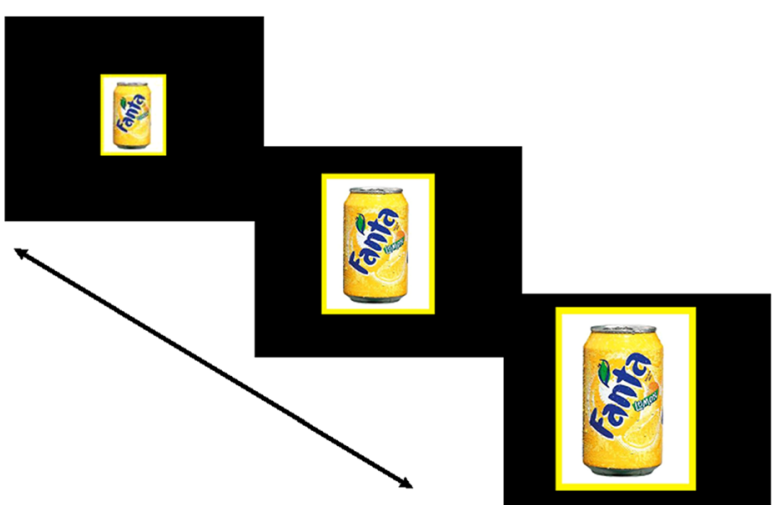

Fig. 1 Schematic overview of a the visual dot probe task (VDP; MacLeod et al. 1986) and $\mathbf{b}$ the approach avoidance task (AAT; Rinck and Becker 2007)

individuals' motivational schema, as we found that drinking motives could predict the strength of the interpretation bias (also see Salemink and Wiers 2014; Woud et al. 2015a). More specifically, individuals who drink alcohol to facilitate or improve social relationships or enhance enjoyment in social situations (social drinking motives) tended to interpret positive scenarios such as a fun evening with friends or a party with alcohol use. Both individuals who drink alcohol for social motives as well as those who drink for coping reasons, on the other hand, tended to interpret negative scenarios (having a bad day, feeling stressed) with alcohol use. This implies that the interpretation bias is not always present but instead may be triggered by certain internal and external contextual cues.

\section{Executive and Cognitive Dysfunctioning}

To study executive and cognitive functioning in problematic drinkers, we first piloted several measures for executive functioning (i.e. Corsi block tapping task, Self-ordered pointing task, Go/No-go task, Stop signal task; Study 7; Van Duijvenbode et al. 2013). Only the Go/No-go task (Newman and Kosson 1986) and Corsi block tapping task (Corsi 1972) remained in our later study to measure executive functioning (inhibitory control and working memory capacity) due to difficulties participants with MBID experienced in conducting the other two tasks. Figure 2 shows a schematic overview of the two tasks. Cognitive functioning was measured using the WAIS-III (Uterwijk 2000). If IQ scores were unknown, cognitive functioning was estimated with a short form of the WAIS-III, which seemed to provide a reliable and valid estimate of IQ in individuals with MBID (study 9; Van Duijvenbode et al. 2016g).

Using these tasks, we explored executive and cognitive functioning in current drinkers. Overall, we found that individuals with MBID had a smaller working memory capacity and also show a weaker inhibitory control compared to individuals without MBID. This means they have more difficulty controlling their behaviour and are more likely to act on impulses (Diamond 2013). More surprisingly, however, is that we found no executive dysfunctioning in problematic drinkers. Problematic drinkers did not have a smaller working memory capacity and did not show less inhibitory control than light drinkers (study 8; Van Duijvenbode et al. 2016f). Although this contradicts previous research, some other studies have also failed to find evidence for executive dysfunctioning in problematic drinkers (e.g. Ellingson et al. 2014; Fernie et al. 2010). With regard to cognitive functioning, we also found no differences between light and problematic drinkers in (estimated) verbal IQ, suggesting that verbal reasoning and vocabulary are relatively intact (also see Bijl et al. 2005). Problematic

Table 2 Examples of the positive, negative and neutral scenarios used (Woud et al. 2012) and possible answers given by participants, derived from Van Duijvenbode et al. (2016e)

\begin{tabular}{lll}
\hline & Scenario & Possible answers \\
\hline Positive scenario & Movie night & New film (alcohol-unrelated) \\
& Movie night at your friends house. "One more?”, one of your friends asks. & $\begin{array}{l}\text { Your glass (ambiguous) } \\
\text { Yeer (alcohol-related) }\end{array}$ \\
& You cannot resist temptation and reach for a ... & Chocolate (alcohol-unrelated) \\
Negative scenario & Bad day & A drink (ambiguous) \\
& It is a horrible day and nothing works. You want to lose this bad feeling & Alcohol (alcohol-related) \\
Neutral scenario & and treat yourself. You get a strong craving for ... & Good (alcohol-unrelated) \\
& Poker & Bad (alcohol-unrelated) \\
& You play poker with your friends every other week. Everything is ready & Difficult to win with (alcohol-unrelated) \\
& and the cards have been dealt. This time, your cards are very ... &
\end{tabular}




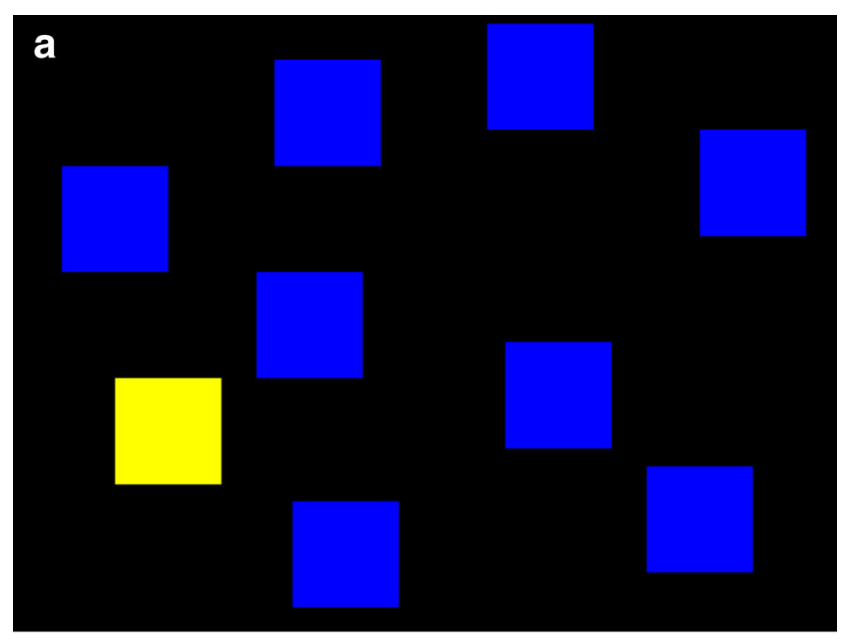

b

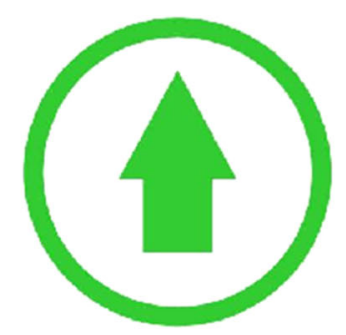

Fig. 2 An overview of the executive control tasks. a the Corsi block tapping task (Corsi 1972). The yellow block symbolises the current block in the sequence. An example of a go trial on the Go/No-go task (Newman and Kosson 1986) is shown in b. Participants were instructed to press a space bar as quickly as possible on go trials and withhold from responding on the no-go trials

drinkers without MBID, however, did show a significantly lower (estimated) performance IQ compared to light drinkers without MBID. This indicates possible impairments in processing speed, problem solving abilities and cognitive and behavioural flexibility in problematic drinkers without MBID. However, problematic drinkers with MBID were not found to have a lower (estimated) performance IQ compared to light drinkers (Study 10; Van Duijvenbode et al. 2016b). Although executive and cognitive functioning were impaired among participants with MBID, we found no additive effects of MBID and problematic alcohol use.

\section{Discussion}

In sum, we have reached our objective to develop and test measures of cognitive biases and executive dysfunctioning in problematic drinkers. Participants with MBID understood the instructions and were able to conduct the tasks - although the reliability of the RT-based tasks for cognitive biases were a concern. Our results regarding the second objective - to study the extent and nature of the influence of IQ and executive control on the cognitive biases by comparing individuals with and without MBID — were mixed and remained inconclusive. Although we did not find attentional or approach biases in problematic drinkers, we did find an interpretation bias in the same sample. Similarly, though we found no executive dysfunctioning in problematic drinkers, aspects of cognitive functioning did seem impaired. While IQ was not related to the strength or manifestation of the attentional and approach bias, it seemed to relate to the strength of the interpretation bias. Although executive and cognitive functioning were impaired among both light and problematic drinkers with MBID, we found no additive effects of problematic alcohol use and MBID on executive or cognitive functioning.

We offer two explanations for our results. First, it is possible that the degree in which neuropsychological functions are affected by substance use varies across individuals. In other words, the strength of the cognitive biases and the degree of executive/cognitive dysfunctioning in problematic drinkers could be influenced by personal and contextual factors. This explanation is supported by our data on the attentional and approach biases, which suggested a large variation in the strength of the biases. Indeed, factors such as current levels of craving (Field et al. 2009), poly-substance use (Marks et al. 2015), co-morbid psychiatric disorders and the use of psychotropic medication (Sinclair et al. 2010) and being in treatment (Field et al. 2014) have been found to influence the strength of the cognitive biases as well as the effects of problematic alcohol use on the brain in individuals without MBID (Petrakis et al. 2002; Parsons 1998). Although co-morbidity between psychiatric disorders, subsequent use of prescribed psychotropic medication and problematic substance use reflects the complex nature of the target group (Center for Substance Abuse Treatment 2007), a possible influence of these comorbid disorders on the cognitive biases and executive and cognitive functioning cannot be ruled out. The complexity and heterogeneity of our samples thus forms both a strength (representative sample, reflecting the complex and diverse nature of the target group) as well as a weakness of our studies, as the diversity of the participants in, for example combinations of used substances, type and degree of psychiatric co-morbidity, and the type of medication described made it difficult to disentangle the precise mechanisms in which these factors influenced our results.

A second explanation for our results concerns the psychometric qualities of the measures we used. In line with results of Ataya et al. (2012), Field and Christiansen (2012), Kersbergen et al. (2015) and Schmukle (2005), we found the internal consistency of the bias scores to be poor. Cronbach's alpha and the mean inter-item correlation were unacceptably low, 
suggesting poor item homogeneity and construct validity. This could explain why we found an interpretation bias in problematic drinkers, but no attentional or approach biases in the same group of participants. In individuals with MBID, the use of RT-based measures was complicated further by a large trial-totrial, intra-individual variability in RT. Individuals with MBID not only showed a slower overall RT, but their RT also fluctuated within the tasks (see also Hunt 2005; Jensen 2006). This has been associated with a difficulty of individuals with MBID to maintain an optimal level of performance (Baumeister and Kellas 1968), for example due to momentary fluctuations in attention or deficiencies in executive functioning such as working memory or information processing speed (Haishi et al. 2011; Schmiedek et al. 2007). What the implications of this intra-individual variability are on the reliability and validity of RT-based measures remains unclear and should be studied further.

Our results provide practical implications that can be translated into the screening, assessment and treatment of problematic drinkers. First, the large variability in the strength of the attentional and approach bias suggests that there are problematic drinkers (and light drinkers) who do show cognitive biases. We advise practitioners to be aware of the possibility of cognitive biases in the information processing of problematic drinkers in their perception and conceptualisation of problematic alcohol use and discuss the potential existence of cognitive biases with clients and/or other caregivers as a component of educating clients about problematic alcohol use (Field et al. 2014).

Second, the large variability in the strength of the attentional and approach bias also suggests that there are problematic drinkers who do not show cognitive biases. Also taking into consideration the problematic psychometric qualities of the measures we have used, we discourage the use of RT-based measures for clinical purposes such as the screening, assessment and treatment of problematic alcohol. After all, establishing the strength of the cognitive biases at a group level has proven to be difficult given the reliability of the measures, let alone the strength of the cognitive biases at an individual level. We therefore discourage the use of these measures to screen for or asses the severity of alcohol use-related problems and do not recommend implementing cognitive bias modification procedures aimed at reducing the cognitive biases (also see critique on these procedures by Christiansen et al. 2015; and Field et al. 2014; and a recent meta-analysis by Cristea et al. 2016 on the ineffectiveness of cognitive bias modification procedures). The clinical relevance of the (less implicit) word association tasks, on the other hand, looks more promising. For example, these tasks could be incorporated into treatment and relapse prevention interventions as a way to identify high-risk situations for alcohol use or relapse (Woud et al. 2012). In addition, preliminary evidence in problematic drinkers without MBID shows that the interpretation bias can be trained in interpretation retraining procedures, although the effectiveness of such a training in reducing the strength of the interpretation bias and subsequent alcohol use was limited (Woud et al. 2015b).

Third, considering the cognitive dysfunctioning in problematic drinkers without MBID, we advise practitioners to consider neurocognitive assessment of cognitive and executive functioning in an early phase of the diagnostic and treatment procedure (also see Bates et al. 2013; Schulte et al. 2014). Identifying executive/cognitive deficiencies improves treatment outcome and success (Copersino et al. 2009) because it allows those with executive/cognitive deficiencies to be entered into treatment interventions more tailored to their needs (McLaughlin et al. 2007). For example, it has been suggested that cognitive dysfunctioning often associated with MBID (e.g. attentional dysfunctioning, impaired organisational and planning skills and impaired self-monitoring) hamper the usefulness of treatment programmes based on cognitive and behavioural change (Allan et al. 2012). Identifying such factors in an early phase of the treatment thus guides practitioners in their choices for treatment interventions. In the assessment of executive/cognitive functioning, we would recommend to cover a broad range of executive/ cognitive functions, because both our (i.e. lower performance but not verbal IQ in problematic drinkers) and other research (e.g. Parsons 1998) suggests that cognitive and executive deficits vary across participants and represent a diffuse pattern of neuropsychological alterations in the brain. Broad spectrum measures such as intelligence tests or standardised test batteries for executive functioning thus seem especially useful for the purpose of neurocognitive assessment.

Fourth and last, taking into account that we found limited and mixed results regarding executive/cognitive dysfunctioning in problematic drinkers, implementing neurocognitive treatment protocols aimed at improving executive/cognitive functioning might not be useful in the treatment of problematic alcohol use at this stage. However, as we did find working memory capacity and inhibitory control to be impaired among individuals with MBID - regardless of the severity of alcohol use-related problems - they could benefit from training procedures aimed at improving executive functioning (also see Van der Molen et al. 2010). In addition, deficiencies in executive/cognitive functioning should be taken into account in the planning and course of the treatment for this group (see Cunha and Novaes 2004). For example, concentrating on the long-term positive consequences of cessation might not be effective in individuals with a low working memory capacity and weak inhibitory control, as these treatment goals will be overruled easily when confronted with the positive, short-term consequences of alcohol use (Diamond 2013). Processing speed could also be taken into account in the planning and course of the treatment, for example by slowing down the pace in treatment protocols, 
increasing the number of treatment sessions and repeating the same information multiple times to ensure optimal understanding by the client. Our research thus underscores previous findings suggesting that treatment interventions for individuals with MBID must be tailored to their needs (e.g. Degenhardt 2000; Kerr et al. 2013).

To conclude, our studies show that problematic alcohol use - in both individuals with and without MBID - is a complex disorder that is likely to be associated with several neuropsychological disruptions. Although we found many similarities between problematic drinkers with and without MBID, we also found some differences between the two groups (i.e. stronger interpretation bias in participants with MBID, no executive and cognitive dysfunctioning in problematic drinkers with MBID), suggesting that problematic drinkers with MBID do in fact form a specific group that should be distinguished from problematic drinkers without MBID. This indicates that problematic alcohol use requires specialised treatment from multidisciplinary teams with sufficient knowledge of both problematic alcohol use and MBID. To achieve this, a close collaboration and cross-fertilisation between addiction medicine and ID service providers is vital.

Acknowledgements Support from several Dutch organisations within ID care (Arduin, Aveleijn, Ipse de Bruggen, Koraalgroep, Leekerweide, Pluryn, Trajectum) and addiction medicine (Brijder, Iriszorg, Tactus) is gratefully acknowledged.

\section{Compliance with Ethical Standards}

Conflict of Interest The authors declare that they have no conflict of interest.

Open Access This article is distributed under the terms of the Creative Commons Attribution 4.0 International License (http:// creativecommons.org/licenses/by/4.0/), which permits unrestricted use, distribution, and reproduction in any medium, provided you give appropriate credit to the original author(s) and the source, provide a link to the Creative Commons license, and indicate if changes were made.

\section{References}

Allan, J., Kemp, M., \& Golden, A. (2012). The prevalence of cognitive impairment in a rural in-patient substance misuse treatment programme. Mental Health and Substance use, 5, 303-313.

American Psychiatric Association (2013). Diagnostic and statistical manual of mental disorders (5th ed.). Washington DC: American Psychiatric Association.

Ames, S. L., Sussman, S., Dent, C. W., \& Stacy, A. W. (2005). Implicit cognition and dissociative experiences as predictors of adolescent substance use. The American Journal of Drug and Alcohol Abuse, $31,129-162$.

Ataya, A. F., Adams, S., Mullings, E., Cooper, R. M., Attwood, A. S., \& Munafo, M. R. (2012). Internal reliability of measures of substancerelated cognitive bias. Drug and Alcohol Dependence, 121, 148-151.
Babor, T. F., Higgins-Biddle, J. C., Saunders, J. B., \& Monteiro, M. G. (2001). AUDIT. The alcohol use disorders identification test: guidelines for use in primary care (2nd ed.). Geneva: World Health Organisation.

Bates, M. E., Buckman, J. F., \& Nguyen, T. T. (2013). A role for cognitive rehabilitation in increasing the effectiveness of treatment for alcohol use disorders. Neuropsychology Review, 23, 27-47.

Baumeister, A. A., \& Kellas, G. (1968). Reaction time and mental retardation. International Review of Research in Mental Retardation, 3, 168-193.

Bijl, S., De Bruin, E. A., Kenemans, J. L., Verbaten, M. N., \& Böcker, K. B. (2005). Effects of chronic alcohol consumption in a visual attention task and an auditory oddball task: an event-related potential study. Alcoholism: Clinical and Experimental Research, 29, 2029-2038.

Burgard, J. F., Donohue, B., Azrin, N. H., \& Teichner, G. (2000). Prevalence and treatment of substance abuse in the mentally retarded population: an empirical review. Journal of Psychoactive Drugs, 32, 293-298.

Carroll Chapman, S. L., \& Wu, L.-T. (2012). Substance abuse among individuals with intellectual disability. Research in Developmental Disabilities, 33, 1147-1156.

Center for Substance Abuse Treatment (2007). The epidemiology of cooccurring substance use and mental disorders. COCE overview paper 8. Rockville, MD: Substance Abuse and Mental Health Services Administration, and Center for Mental Health Services.

Christiansen, P., Schoenmakers, T. M., \& Field, M. (2015). Less than meets the eye: reappraising the clinical relevance of attentional bias in addiction. Addictive Behaviors, 44, 43-50.

Copersino, M. L., Fals-Steward, W., Fitzmaurice, G., Schretlen, D. J., Sokoloff, J., \& Weiss, R. D. (2009). Rapid cognitive screening of patients with substance disorder. Experimental and Clinical Psychopharmacology, 17, 337-344.

Corsi, P. M. (1972). Human memory and the medial temporal regions of the brain. Dissertation Abstracts International, 34, 819B.

Cristea, I. A., Kok, R. N., \& Cuijpers, P. (2016). The effectiveness of cognitive bias modification interventions for substance addictions: a meta-analysis. PloS One, 11(9), e0162226.

Cunha, P. J., \& Novaes, M. A. (2004). Neurocognitive assessment in alcohol abuse and dependence: implications for treatment. Revista Brasileira de Psiquiatria, 26(Supl. 1), 23-27.

Degenhardt, L. (2000). Interventions for people with alcohol use disorders and an intellectual disability: a review of the literature. Journal of Intellectual and Developmental Disabilities, 25, 135-146.

Diamond, A. (2013). Executive functions. Annual Review of Psychology, 64, 135-168.

Ellingson, J. M., Flemming, K. A., Verges, A., Barthowos, B. D., \& Sher, K. J. (2014). Working memory as a moderator of impulsivity and alcohol involvement: testing the cognitive-motivational theory of alcohol use with prospective and working memory updating data. Addictive Behaviors, 39, 1622-1631.

Fernie, G., Cole, J. C., Goudie, A. J., \& Field, M. (2010). Risk-taking but not response inhibition or delay discounting predict alcohol consumption in social drinkers. Drug and Alcohol Dependence, 112, 54-61.

Field, M., \& Christiansen, P. (2012). Commentary on Ataya et al. (2012), 'Internal reliability of measures of substance-related cognitive bias'. Drug and Alcohol Dependence, 124, 189-190.

Field, M., Munafo, M. R., \& Franken, I. H. A. (2009). A meta-analytic investigation of the relationship between attentional bias and subjective craving in substance abuse. Psychological Bulletin, 135, 589-607.

Field, M., Marhe, R., \& Franken, I. H. A. (2014). The clinical relevance of attentional bias in substance use disorders. CNS Spectrums, 19, 225-230

Greenwald, A. G., Banaji, M. R., Rudman, L. A., Farnham, S. D., Nosek, B. A., \& Mellot, D. S. (2002). A unified theory of implicit attitudes, stereotypes, self-esteem and self-concept. Psychological Review, $109,3-25$.

Haishi, K., Okuzumi, H., \& Kokubun, M. (2011). Effects of age, intelligence and executive control function on saccadic reaction time in 
persons with intellectual disabilities. Research in Developmental Disabilities, 32, 2644-2650.

Hobson, J., Bruce, G., \& Butler, S. H. (2013). A flicker change blindness task employing eye tracking reveals an association with levels of craving not consumption. Journal of Psychopharmacology, 27, 93-97.

Hunt, E. (2005). Information processing and intelligence: where we are and where we are going. In R. J. Sternberg \& J. E. Pretz (Eds.), Cognition and intelligence: identifying mechanisms of mind (pp. 1-25). Cambridge: Cambridge University Press.

Hyman, S. E., Malenka, R. C., \& Nestler, E. J. (2006). Neural mechanisms of addiction: the role of reward-related learning and memory. Annual Review of Neuroscience, 29, 565-598.

Jensen, A. R. (2006). Clocking the mind: mental chronometry and individual differences. Oxford: Elsevier Ltd..

Josman, N., Klinger, E., \& Kizony, R. (2008). Performance within the virtual action planning supermarket (VAP-S): An executive function profile of three different populations suffering from deficits in the central nervous system. Proceedings of the 7th International Conference on Disability, Virtual Reality and Associated Technologies, pp. 33-38.

Kerr, S., Lawrence, M., Darbyshire, C., Middleton, A. R., \& Fitzsimmons, L. (2013). Tobacco and alcohol-related interventions for people with mild/moderate intellectual disabilities: a systematic review of the literature. Journal of Intellectual Disability Research, 57, 393-408.

Kersbergen, I., Woud, M. L., \& Field, M. (2015). The validity of different measures of automatic alcohol action tendencies. Psychology of Addictive Behaviors, 29, 225-230.

Koob, G. F. (2013). Addiction is a reward deficit and stress surfeit disorder. Frontiers in Psychiatry, 4, 1-18.

Krank, M. D., Schoenfeld, T., \& Frigon, A. P. (2010). Self-coded indirect memory associations and alcohol and marijuana use in college students. Behavior Research Methods, 42, 733-738.

MacLeod, C. M., Mathews, A., \& Tata, P. (1986). Attentional bias in emotional disorders. Journal of Abnormal Psychology, 95, 15-20.

Marks, K. R., Pike, E., Stoops, W. W., \& Rush, C. R. (2015). The magnitude of drug attentional bias is specific to substance use disorder. Psychology of Addictive Behaviors, 29, 690-695.

McGillicuddy, N. B. (2006). A review of substance use research among those with mental retardation. Mental Retardation and Developmental Disabilities Research Reviews, 12, 41-47.

McLaughlin, D. F., Taggart, L., Quinn, B., \& Milligan, V. (2007). The experiences of professionals who care for people with intellectual disability who have substance-related problems. Journal of Substance Use, 12, 133-143.

Nestler, E. J. (2005). Is there a common molecular pathway for addiction? Nature Neuroscience, 8, 1445-1449.

Newman, J. P., \& Kosson, D. S. (1986). Passive avoidance learning in psychopathic and nonpsychopathic offenders. Journal of Abnormal Psychology, 95, 252-260.

Parsons, O. A. (1998). Neurocognitive deficits in alcoholics and social drinkers: a continuum? Alcoholism: Clinical and Experimental Research, 22, 954-961.

Petrakis, I. L., Gonzalez, G., Rosenheck, R., \& Krystal, J. H. (2002). Comorbidity of alcoholism and psychiatric disorders. Alcohol Research and Health, 26, 81-89.

Ranganath, K. A., Smith, C. T., \& Nosek, B. A. (2008). Distinguishing automatic and controlled components of attitudes from direct and indirect measurement methods. Journal of Experimental Social Psychology, 44, 386-396.

Rinck, M., \& Becker, E. S. (2007). Approach and avoidance in fear of spiders. Journal of Behavioral Therapy and Experimental Psychiatry, 38, 105-120.

Robinson, T. E., \& Berridge, K. C. (2008). The incentive sensitization theory of addiction: some current issues. Philosophical Transaction of the Royal Society of London: Series B, Biological Sciences, 363, 3137-3146.

Salemink, E., \& Wiers, R. W. (2014). Alcohol-related memory associations in positive and negative affect situations: drinking motives, working memory capacity, and prospective drinking. Psychology of Addictive Behaviors, 28, 105-113.

Schippers, G. M., \& Broekman, T. G. (2010). De AUDIT. Nederlandse vertaling van de Alcohol Use Disorders Identification Test [Dutch translation of the Alcohol Use Disorders Identification Test]. Retrieved from http://www.mateinfo.nl/audit/.

Schmiedek, F., Oberauer, K., Wilhelm, O., Süss, H.-M., \& Wittmann, W. W. (2007). Individual differences in components of reaction time distributions and their relations to working memory and intelligence. Journal of Experimental Psychology: General, 136, 414-429.

Schmukle, S. C. (2005). Unreliability of the dot probe task. European Journal of Personality, 19, 595-605.

Schulte, M. H. J., Cousijn, J., Den Uyl, T. E., Goudriaan, A. E., Van den Brink, W., Veltman, D. J., Schilt, T., \& Wiers, R. W. (2014). Recovery of neurocognitive functions following sustained abstinence after substance dependence and implications for treatment. Clinical Psychology Review, 34, 531-550.

Sinclair, J. M. A., Nausheen, B., Garner, M. J., \& Baldwin, D. S. (2010). Attentional bias in clinical populations with alcohol use disorders: is co-morbidity ignored? Human Psychopharmacology, 25, 515-524.

Slayter, E. M. (2008). Understanding and overcoming barriers to substance abuse treatment access for people with mental retardation. Journal of Social Work in Disability and Rehabilitation, 7, 63-80.

Stacy, A. W., \& Wiers, R. W. (2010). Implicit cognition and addiction: a tool for explaining paradoxical behavior. Annual Review of Clinical Psychology, 6, 551-575.

To, W. T., Neirynck, S., Vanderplasschen, W., Vanheule, S., \& Vandevelde, S. (2014). Substance use and misuse in persons with intellectual disabilities (ID): results of a survey in ID and addiction services in Flanders. Research in Developmental Disabilities, 35, 1-9.

Uterwijk, J. M. R. (2000). WAIS-III: Nederlandstalige bewerking: Wechsler Adult Intelligence Scale-Ed. 3: Afname en scoringshandleiding (WAIS-III 2000). Lisse: Swets Test Publishers.

Van der Molen, M. J., Van Luit, J. E. H., Van der Molen, M. W., Klugkist, I., \& Jongmans, M. J. (2010). Effectiveness of a computerised working memory training in adolescents with mild to borderline intellectual disabilities. Journal of Intellectual Disability Research, 54, 433-447.

Van Duijvenbode, N., Didden, R., Bloemsaat, G., \& Engels, R. C. M. E. (2012a). Problematic alcohol use and mild intellectual disability: standardization of pictorial stimuli fora $\mathrm{n}$ alcohol cue reactivity task. Research in Developmental Disabilities, 33, 1095-1102.

Van Duijvenbode, N., Didden, R., Voogd, H., Korzilius, H. P. L. M., \& Engels, R. C. M. E. (2012b). Cognitive biases in individuals with mild to borderline intellectual disability and alcohol use-related problems. Research in Developmental Disabilities, 33, 1928-1936.

Van Duijvenbode, N., Didden, R., Korzilius, H. P. L. M., Trentelman, M., \& Engels, R. C. M. E. (2013). Executive control in long-term abstinent alcoholics with mild to borderline intellectual disability: the relationship with IQ and severity of alcohol use-related problems. Research in Developmental Disabilities, 34, 3583-3595.

Van Duijvenbode, N., VanDerNagel, J. E. L., Didden, R., Engels, R. C. M. E., Buitelaar, J. K., Kiewik, M., \& De Jong, C. A. J. (2015). Substance use disorders in individuals with mild to borderline intellectual disability: current status and future directions. Research in Developmental Disabilities, 38, 319-328.

Van Duijvenbode, N., Didden, R., Korzilius, H. P. L. M., \& Engels, R. C. M. E. (2016a). The addicted brain: cognitive biases in problematic drinkers with mild to borderline intellectual disability. Journal of Intellectual Disability Research, 60, 242-253.

Van Duijvenbode, N., Didden, R., VanDerNagel, J. E. L., Korzilius, H. P. L. M., \& Engels, R. C. M. E. (2016b). Cognitive deficits in 
problematic drinkers with and without mild to borderline intellectual disability. Journal of Intellectual Disabilities.

Van Duijvenbode, N., Didden, R., Korzilius, H. P. L. M., \& Engels, R. C. M. E. (2016c). Attentional bias in problematic drinkers with mild to borderline intellectual disability. Journal of Intellectual Disability Research.

Van Duijvenbode, N., Didden, R., (2016d). The relationship between drinking motives and interpretation bias in VanDerNagel, J. E. L., Korzilius, H. P. L. M., \& Engels, R. C. M. E. problematic drinkers with and without mild to borderline intellectual disability. Journal of Intellectual Disability Research.

Van Duijvenbode, N., Didden, R., Korzilius, H. P. L. M., \& Engels, R. C. M. E. (2016e). Everybody is... drinking! Interpretation bias in problematic drinkers with mild to borderline intellectual disability. Journal of Mental Health Research in Intellectual Disabilities, 9, 101-117.

Van Duijvenbode, N., Didden, R., Korzilius, H. P. L. M., \& Engels, R. C. M. E. (2016f). The role of executive control and readiness to change in problematic drinkers with mild to borderline intellectual disability. Journal of Applied Research in Intellectual Disabilities.

Van Duijvenbode, N., Didden, R., Van den Hazel, T., \& Engels, R. C. M. E. (2016g). Psychometric qualities of a tetrad WAIS-III short form for use in individuals with mild to borderline intellectual disability. Developmental Neurorehabilitation, 19, 26-30.

Vollstädt-Klein, S., Loeber, S., Von der Goltz, C., Mann, K., \& Kiefer, F. (2009). Avoidance of alcohol-related stimuli increases during the early stage of abstinence in alcohol-dependent patients. Alcohol \& Alcoholism, 44, 458-463.

Wilson, T. D., Lindsey, S., \& Schooler, T. Y. (2000). A model of dual attitudes. Psychological Review, 107, 101-126.

Woud, M. L., Fitzgerald, D. A., Wiers, R. W., Rinck, M., \& Becker, E. S. (2012). 'Getting into the spirit': alcohol-related interpretation bias in heavy-drinking students. Psychology of Addictive Behaviors, 26, 627-632.

Woud, M. L., Pawelczak, S., Rinck, M., Lindenmeyer, J., Souren, P., Wiers, R. W., \& Becker, E. S. (2014). Alcohol-related interpretation bias in alcohol-dependent patients. Alcoholism: Clinical and Experimental Research, 38, 1151-1159.

Woud, M. L., Becker, E. S., Rinck, M., \& Salemink, E. (2015a). The relationship between drinking motives and alcohol-related interpretation bias. Journal of Behavior Therapy and Experimental Psychiatry, 47, 102-110.

Woud, M. L., Hutschemaekers, M. H. M., Rinck, M., \& Becker, E. S. (2015b). The manipulation of alcohol-related interpretation biases by means of cognitive bias modification-interpretation (CBM-I). Journal of Behavior Therapy and Experimental Psychiatry, 49, 61-68.

Yücel, M., \& Lubman, D. I. (2007). Neurocognitive and neuroimaging evidence of behavioural dysregulation in human drug addiction: implications for diagnosis, treatment and prevention. Drug and Alcohol Review, 26, 33-39. 